\title{
Land use changes and their impact on Soil and vegetation properties over Kanshi watershed, Potohar Plateau, Pakistan
}

\author{
Sohail Abbas ${ }^{1}$ and Shehla Jabeen ${ }^{2}$ \\ ${ }^{1}$ Konkuk University \\ ${ }^{2}$ University of Jhang
}

March 26, 2021

\begin{abstract}
Large scale changes in land use pattern such as deforestation and machine-intensive farming process have increased carbon concentrations in atmosphere which negatively affects agricultural sector. Cross-disciplinary approaches were applied to investigate the land use changes and their impacts on the soil properties over Kanshi watershed. The results revealed that vegetation cover has been declined over the Kanshi catchment area during the last two decades. The deforestation and urbanization are the basic reasons for the fall of water tables in the Kanshi catchment area. Furthermore, the decreasing trend of rainfall and increasing trend of temperature was estimated during the last two decades. While the water discharge was decreased by 44.15 $\%$ during the last two decades in the Kanshi watershed. This substantial and significant change resultant due to climate change or increased intercession of anthropogenic activities on the earth surface. The highest stream flow was found in 1992 in the Kanshi catchment due to heavy rainfall. But in 2019, flow was on its peak value. Such variations in flow of stream increase due to fluctuations in rainfall pattern and vegetation cover resulted land degradation. $85 \%$ of local community is agreed that extensive agricultural practices, population growth, settlement patterns and brick industry have significant negative impact on vegetative cover and water discharge.
\end{abstract}

\section{Hosted file}

Paper; Land Degradation and Development.pdf available at https://authorea.com/users/404152/ articles/515431-land-use-changes-and-their-impact-on-soil-and-vegetation-propertiesover-kanshi-watershed-potohar-plateau-pakistan

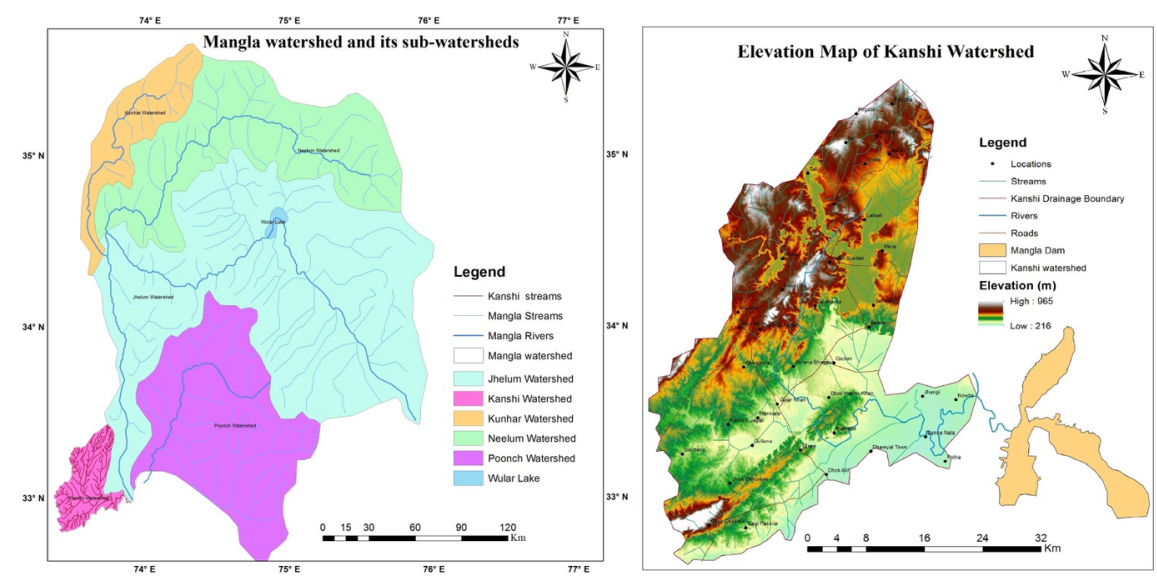




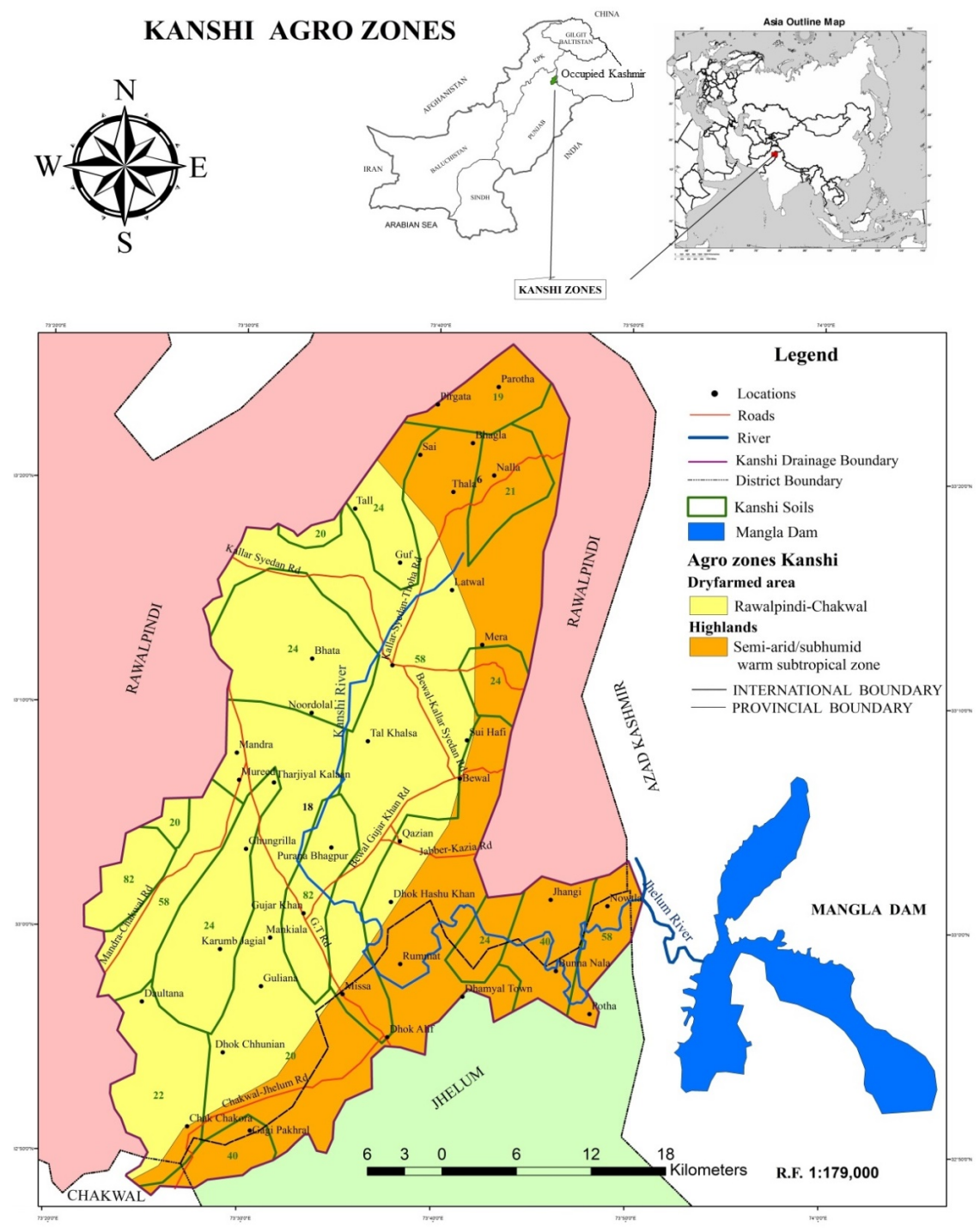



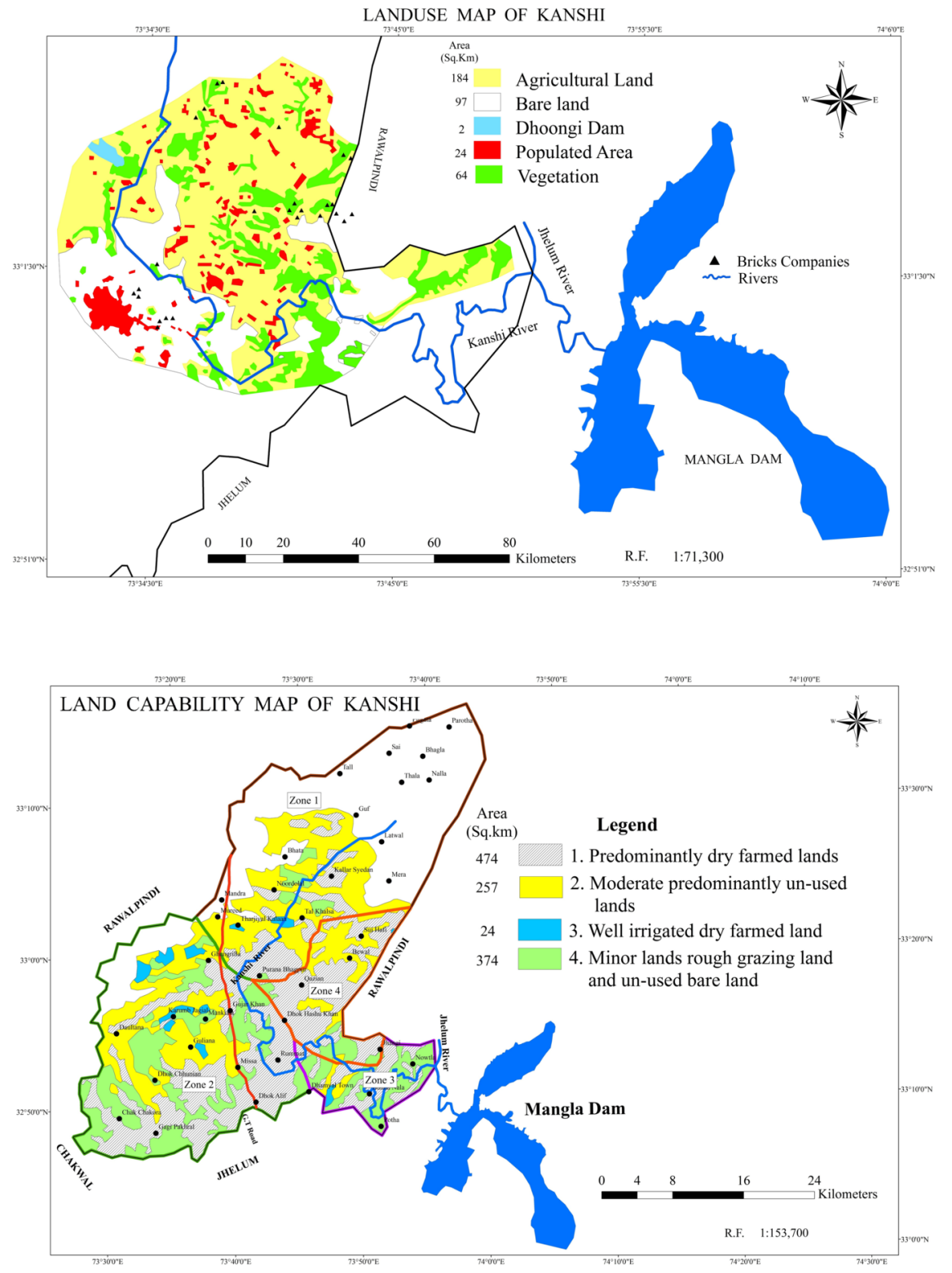


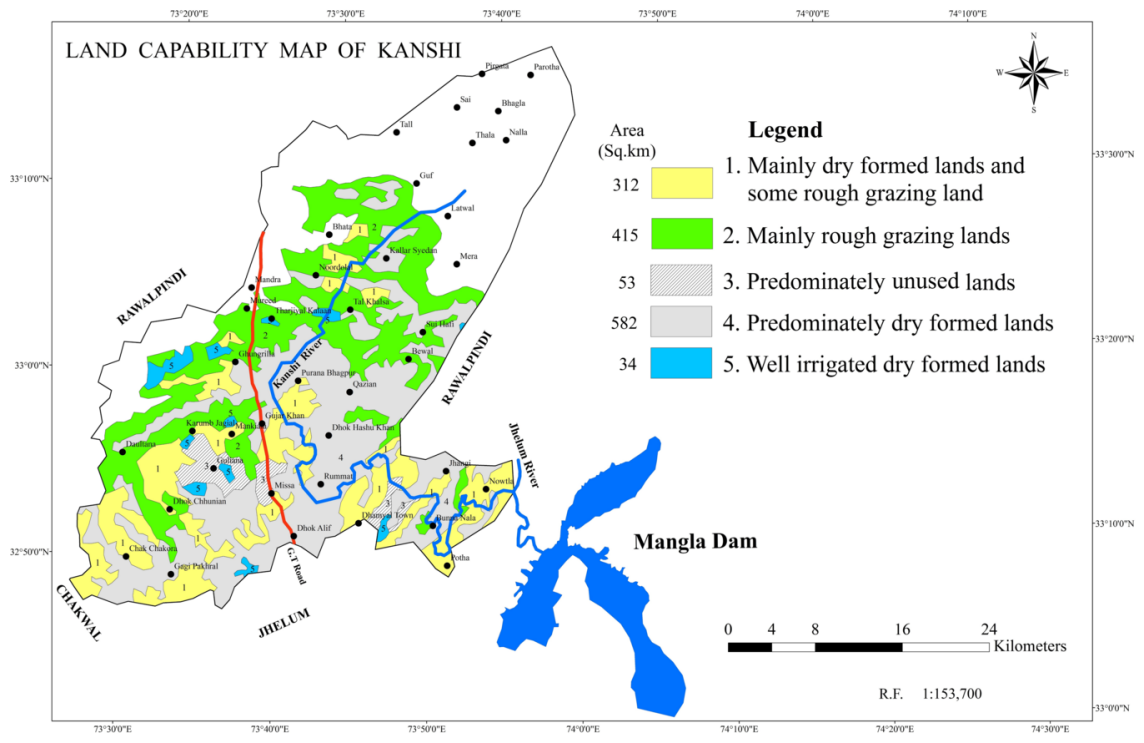




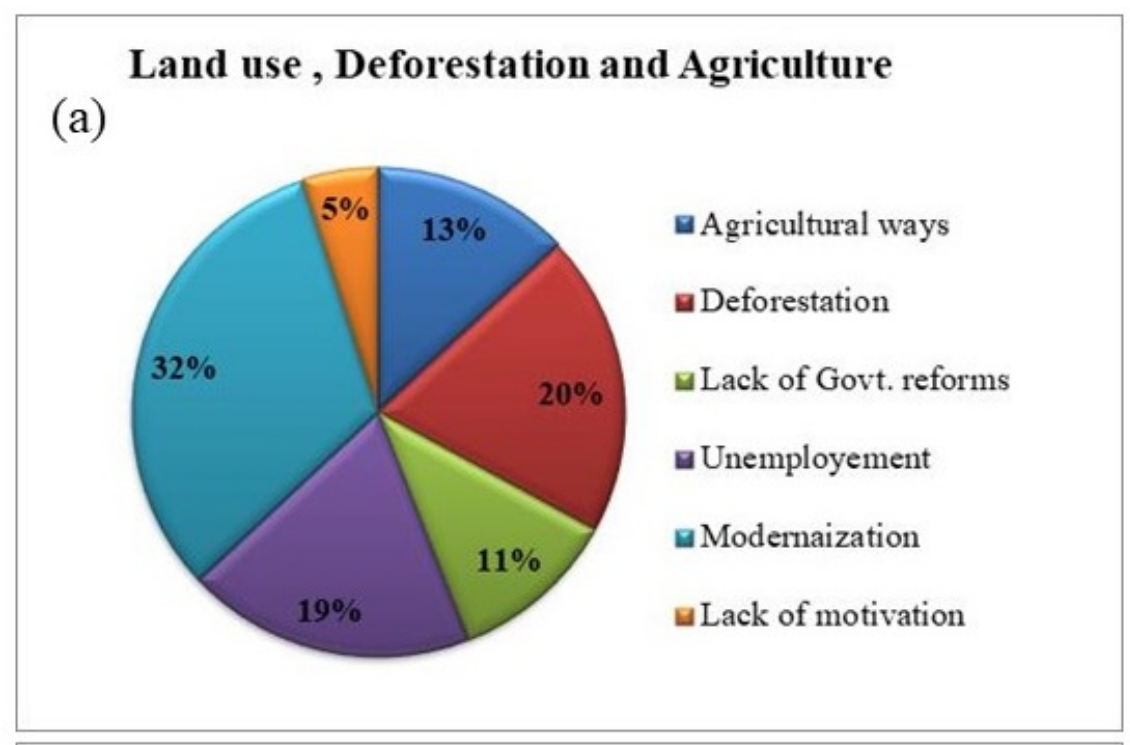

\section{Land Cover patterns and water conservation}

(b)

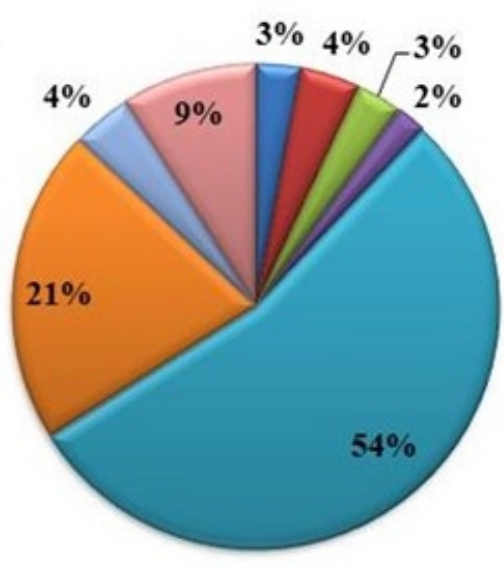

$\square$ Land cover/ Agricuture

Q Streams bank issues

Water storage

Soil erosion

$\square$ Forest degradation

$\square$ water conservation (Dam)

$\square$ land capability

$\square$ Public health cleanliness 

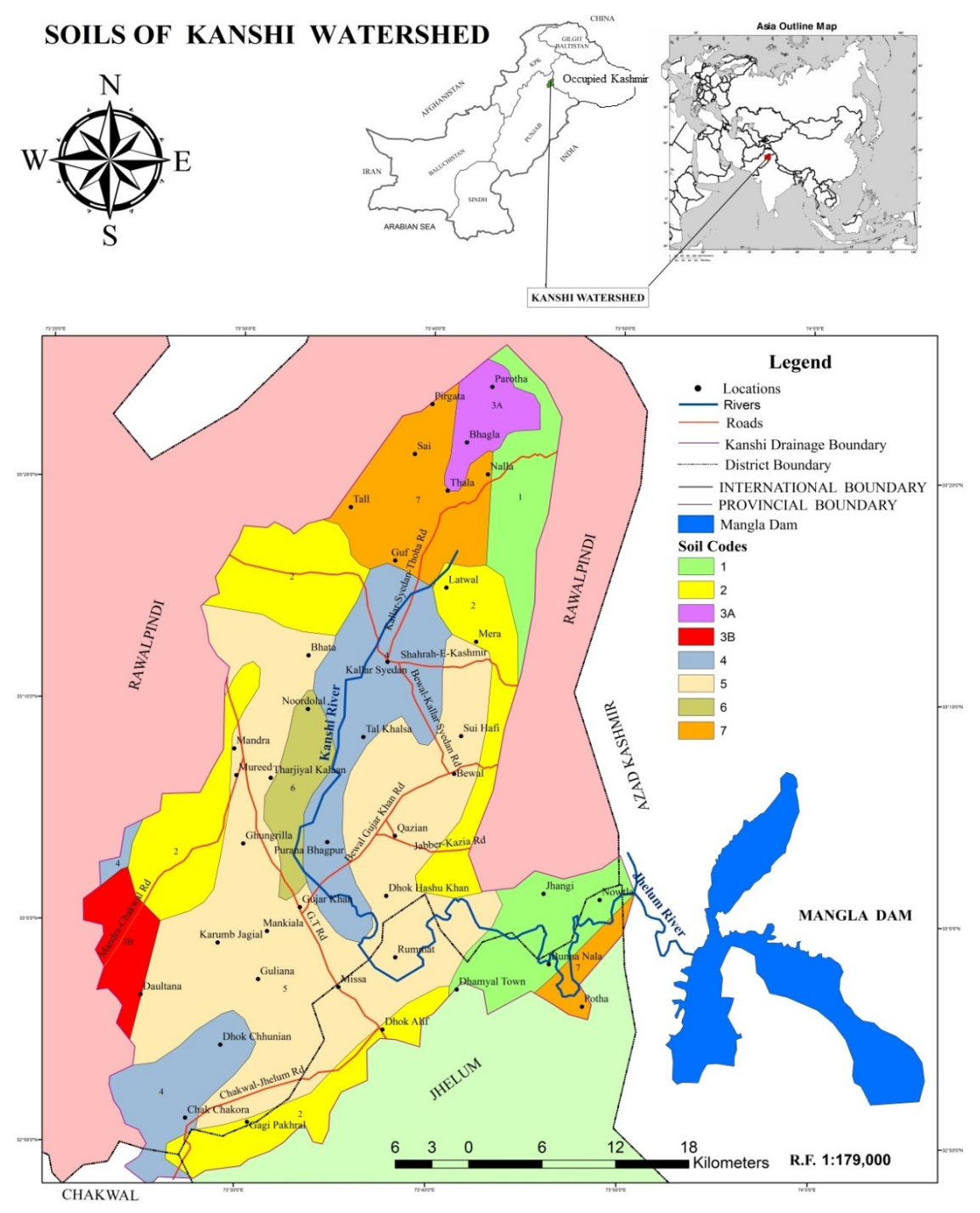